\title{
GMR
}

\section{Genetic diversity and population structure of Castanopsis eyrei based on simple sequence repeat markers}

\author{
L.H. Mao ${ }^{1,2 *}$, X.L. Zhou ${ }^{1,2 *}$ and Y.M. Fang ${ }^{1,2}$ \\ ${ }^{1}$ Collaborative Innovation Center for Southern Modern Forestry, \\ Nanjing Forestry University, Nanjing, China \\ ${ }^{2}$ College of Biology and the Environment, Nanjing Forestry University, \\ Nanjing, China \\ *These authors contributed equally to this study. \\ Corresponding author: Y.M. Fang \\ E-mail: jwu4@njfu.edu.cn
}

Genet. Mol. Res. 15 (2): gmr.15028256

Received December 11, 2015

Accepted February 11, 2016

Published May 6, 2016

DOI http://dx.doi.org/10.4238/gmr.15028256

\begin{abstract}
Castanopsis eyrei (Fagaceae) is one of the dominant tree species in mid-subtropical, evergreen, broad-leaved forests. We obtained 14 pairs of simple sequence repeat (SSR) primers from previous studies, which were used to analyze $90 \mathrm{C}$. eyrei individuals from three populations at different altitudes. Low heterozygosity was detected $\left(F_{i s}=0.6124\right)$, and the observed heterozygosity was lower than the expected heterozygosity, possibly because of inbreeding and/ or the population substructure. The genetic differentiation between populations was relatively low $\left(F_{s t}=0.0645\right)$; only $7 \%$ of the total genetic variation occurred between populations. The medium-altitude population had higher genetic diversity than the low-altitude or highaltitude populations.
\end{abstract}

Key words: Castanopsis eyrei; Genetic diversity; Population structure; SSR 


\section{INTRODUCTION}

The mid-subtropical zone of China is covered with forests dominated by broad-leaved evergreen trees. Wuyishan National Nature Reserve is a world cultural and natural heritage site, and contains a number of tree species in the well-preserved, broad-leaved evergreen forest (Fang, 2005). Castanopsis eyrei (Fagaceae) is one of the dominant species in mid-subtropical evergreen broad-leaved forests (Hu et al., 2009), and is an important part of forest ecosystems in the subtropical zone of China. C. eyrei is important for water conservation, biodiversity protection, biomass maintenance, and local climate regulation (Ren and Xue, 2008; Ren et al., 2010).

Research on C. eyrei has primarily focused on its community characteristics (Jin, 1998), population structure and dynamics (Xu et al., 2005), and intra- and interspecific competition (Xu et al., 2005). Li and Jin (2006) studied the population genetic diversity of this species at different successional stages of communities on Tiantai Mountain using random amplified polymorphic DNA (RAPD) markers. They found that $75 \%$ of the genetic variation was within populations and $25 \%$ was between populations. Based on inter simple sequence repeat (ISSR) markers, Jin et al. (2007) also reported higher genetic variation within populations than between populations in this species, and that genetic distance was significantly positively correlated with geographical distance.

Simple sequence repeats (SSRs) are tandem-repeated units that are abundant and widely distributed in genomes (Tóth et al., 2000). SSR markers appear to be variable and, because of their co-dominance and high reproducibility, are greatly superior to other markers such as RAPD, ISSR, and amplified fragment length polymorphism (AFLP) (Wang and Szmidt, 2001). Many studies based on SSR markers have proved that they are highly efficient for the assessment of genetic variation within and between populations of plants (Cao et al., 2006; Torres-Díaz et al., 2007; Emanuelli et al., 2013).

With changing altitude, habitats change due to the changing climate, terrain, and vegetation (Sáenz-Romero and Tapia-Olivares, 2003; Sáenz-Romero et al., 2006), and the genetic pattern of a single species may differ with altitude. The genetic differentiation of populations at different altitudes has been detected in some species (Bellusci et al., 2005; Zhang, 2006); however, some studies have reported little or no genetic variation between populations at different altitudes (Aradhya et al., 1993; Oyama et al., 1993; Gehring and Delph, 1999). In this study, SSR markers, combined with population genetic theory, were used to study the genetic diversity and population genetic structure of $C$. eyrei with changing altitude. By understanding the relationship between altitude and population genetic differentiation, suitable strategies can be developed for the production and usage of this species.

\section{MATERIAL AND METHODS}

\section{Sampling}

Naturally grown $C$. eyrei individuals were collected from three populations at three altitudes in Wuyishan National Nature Reserve, where there is relatively little human activity. Leaves of 30 randomly selected plants were sampled from each population, and the interval between adjacent individuals was at least $30 \mathrm{~m}$. After collection, the leaves were dried and stored in silica gel. The locations of the populations studied are presented in Table 1. 
Table 1. Sampling locations for Castanopsis eyrei populations.

\begin{tabular}{l|c|c|c|c}
\hline Population & Latitude $(\mathrm{N})$ & Longitude $(\mathrm{E})$ & Altitude $(\mathrm{m})$ & Sampling size \\
\hline SYG & $27^{\circ} 41.1^{\prime}$ & $117^{\circ} 53.9^{\prime}$ & 492 & 30 \\
\hline DAY & $27^{\circ} 53^{\prime}$ & $117^{\circ} 50.7^{\prime}$ & 699 & 30 \\
\hline WSK & $27^{\circ} 43.3^{\prime}$ & $117^{\circ} 40.1^{\prime}$ & 1200 & 30 \\
\hline
\end{tabular}

\section{DNA extraction and polymerase chain reaction (PCR) amplification}

Total DNA was extracted from the silica gel-dried leaves using a modified 2X CTAB procedure (Doyle and Doyle, 1987). The 14 SSR markers (Table 2) used in the present study were selected based on their ability to amplify DNA in this species, and the reproducibility of their products. DNA amplifications were performed in $20-\mathrm{mL}$ reaction volumes containing $1 \mathrm{X}$ reaction buffer (TaKaRa), 10-15 ng genomic DNA, $250 \mathrm{mM}$ each dNTP, $20 \mathrm{mM}$ each primer, and $1 \mathrm{U}$ Taq DNA polymerase (Takara). The PCR was programmed according to the following profile: $94^{\circ} \mathrm{C}$ for $5 \mathrm{~min}$, followed by 30 cycles at $94^{\circ} \mathrm{C}$ for $45 \mathrm{~s}$, annealing temperature for 45 $\mathrm{s}, 72^{\circ} \mathrm{C}$ for $45 \mathrm{~s}$, and a final extension at $72^{\circ} \mathrm{C}$ for $5 \mathrm{~min}$. A $1-\mu \mathrm{L}$ aliquot of each sample was separated on $8 \%$ denaturing polyacrylamide gel using silver staining. A 50-bp DNA ladder (Takara) was used to identify alleles (Figure 1).

Table 2. Characteristic of the fourteen SSRs studied.

\begin{tabular}{l|c|c|c|c}
\hline Locus & Size rang $(\mathrm{bp})$ & Annealing temperature $\left({ }^{\circ} \mathrm{C}\right)$ & Repeat sequence & References \\
\hline Ccu62F15 & $141-163$ & 52 & (TC)17 & Ueno et al., 2003 \\
\hline Ccu9017 & $156-190$ & 65 & (TC)23 & Ueno et al., 2003 \\
\hline Ccu87F23 & $267-289$ & 58 & (TC)19 & Ueno et al., 2003 \\
\hline Cch10 & $184-199$ & 62 & CAAC(CA)2GAAC & Huang et al., 2009 \\
\hline Cch12 & $150-175$ & 60 & Huang et al., 2009 \\
\hline Cch14 & $153-157$ & 62 & (CACCCA)5 3ATTCTT(TC)14 & Huang et al., 2009 \\
\hline CcC01471 & $110-173$ & 55 & Ueno et al., 2009 \\
\hline CcC02014 & $201-220$ & 55 & (TC)11TGTGATCGATCGCCGAGAAA(GAA)6 & Ueno et al., 2009 \\
\hline CcC02069 & $117-129$ & 55 & (TGT)7 7 & Ueno et al., 2009 \\
\hline CC4323 & 240 & 60 & (CAC)6 & Li and Sun, 2012 \\
\hline CC3754 & 294 & 57 & (GT)8 & Li and Sun, 2012 \\
\hline CC2448 & 175 & 56 & (CAT)6 & Li and Sun, 2012 \\
\hline CC1944 & 239 & 57 & (AGCT)4 & Li and Sun, 2012 \\
\hline CC125 & 281 & 54 & & Li and Sun, 2012 \\
\hline
\end{tabular}

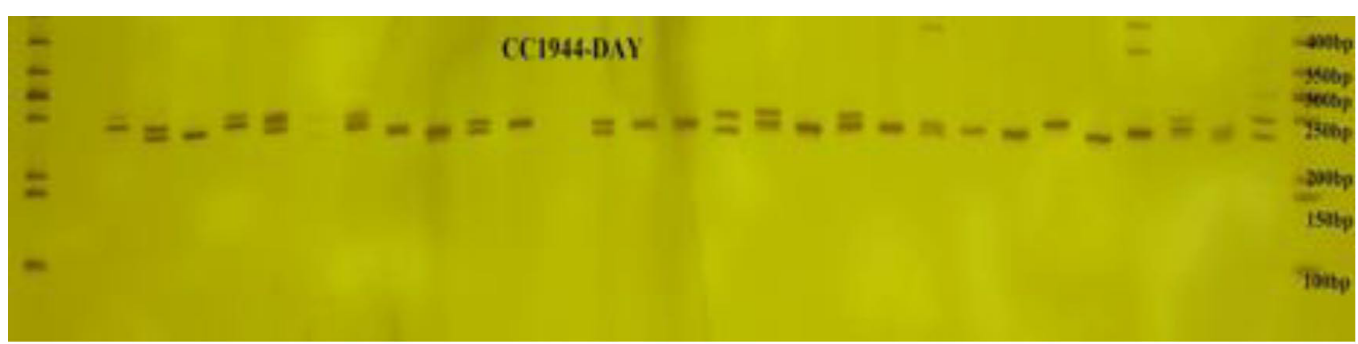

Figure 1. Amplification patterns of primer CC1944 in population DAY.

\section{Data analysis}

The number of alleles $(A)$, the number of effective alleles $(A e)$, the observed 
heterozygosity $(\mathrm{Ho})$, the expected heterozygosity $\left(H_{\mathrm{E}}\right)$, heterozygosis deficiency $\left(F_{i s}\right)$, and the gene differentiation coefficient $\left(F_{s t}\right)$ were all generated using the program POPGENE1.32 (Yeh and Boyle, 1997). We conducted an analysis of molecular variance (AMOVA) using the software program GenAlEx 6.5 (Peakall and Smouse, 2012). A principal coordinates analysis (PCoA) based on the Nei and Li (1979) distance coefficient was performed in GenAlEx 6.5.

\section{RESULTS}

\section{Microsatellite diversity}

The total number of alleles per locus is listed in Table 3. A total of 93 alleles were detected, and the mean number of alleles per locus was 6.6. All 14 of the loci assayed exhibited a high level of polymorphism, with the number of effective alleles per locus ranging from 2.4487 at CC2448 to 8.5906 at CC1944. The observed heterozygosity ranged from 0.0625 to 0.4699 , with an average of 0.2750 . The average expected heterozygosity had slightly higher values than $H o$, and ranged from 0.5312 to 0.8197 , with a mean of 0.7590 .

Table 3. Parameters of variability calculated for the 14 pairs of SSR markers in 90 accessions.

\begin{tabular}{l|c|c|c|c}
\hline Locus & $A$ & $A e$ & $H_{\mathrm{O}}$ & $H_{\mathrm{E}}$ \\
\hline Ccu62F15 & 5 & 3.150 & 0.2683 & 0.7379 \\
\hline Ccu90T17 & 7 & 4.7302 & 0.0625 & 0.7785 \\
\hline Ccu87F23 & 7 & 4.7149 & 0.4382 & 0.7589 \\
\hline Cch10 & 5 & 3.0706 & 0.1034 & 0.5312 \\
\hline Cch12 & 7 & 6.4712 & 0.3750 & 0.8197 \\
\hline Cch14 & 5 & 3.1420 & 0.4699 & 0.6676 \\
\hline CcC0201471 & 8 & 5.6008 & 0.1549 & 0.7767 \\
\hline CcC02069 & 7 & 4.7964 & 0.4205 & 0.7274 \\
\hline CC4323 & 8 & 4.5234 & 0.2809 & 0.7252 \\
\hline CC2448 & 6 & 4.9959 & 0.5000 & 0.7705 \\
\hline CC1944 & 5 & 4.3493 & 0.0714 & 0.6998 \\
\hline CC125 & 6 & 2.4487 & 0.3500 & 0.5645 \\
\hline Mean & 6 & 8.5906 & 0.2738 & 0.8004 \\
\hline St Dev & 6.6429 & 3.0652 & 0.2750 & 0.6444 \\
\hline A & 1.6458 & 4.5939 & 0.1570 & 0.7590 \\
\hline
\end{tabular}

$\mathrm{A}=$ Number of different alleles; $A e=$ effective number of alleles; $H_{\mathrm{O}}=$ observed heterozygosity; $H_{\mathrm{E}}=$ unbiased expected heterozygosity.

The fixation index indicates whether there is a heterozygosis deficiency $\left(F_{i s}>0\right)$ or excess $\left(F_{i s}<0\right)$. The $F_{i s}$ of all of the 14 loci was higher than 0 , indicating a heterozygote deficiency in the three populations (Table 4$)$. The mean value of $H_{\mathrm{O}}(0.2750)$ was significantly lower than the mean value of $H_{\mathrm{E}}(0.7590)$, indicating that mating in this species deviates from a random pattern (Table 5). The $F_{s t}$, which indicates genetic differentiation between populations, varied between loci (0.0139-0.3140), with a mean of 0.0645 .

\section{Genetic variation within and between populations}

We estimated the genetic variation between populations using Wright's analysis of hierarchical F-statistics (Wright, 1965). The mean value of $F_{s t}(0.0645)$ suggested that this species has most genetic variation within, rather than between, its populations. The AMOVA 
analysis (Table 6) suggested that $7 \%$ of the total molecular variance was attributable to betweenpopulation diversity $(\mathrm{P}<0.001)$, while the rest $(93 \%)$ was associated with differences within populations. The PCoA (Figure 2) also indicated that individuals from different populations were not distinct from each other.

Table 4. F statistics (Wright,1965) following the method of Nei (1987) for fourteen polymorphic loci across three natural populations of Castanopsis eyrie.

\begin{tabular}{l|l|l|c}
\hline Locus & $F_{\text {is }}$ & $F_{\text {st }}$ & $N_{m}$ \\
\hline Ccu62F15 & 0.6033 & 0.0788 & 2.9233 \\
\hline Ccu90T17 & 0.9219 & 0.0139 & 17.7655 \\
\hline Ccu87F23 & 0.4209 & 0.0372 & 6.4774 \\
\hline Cch10 & 0.8001 & 0.3140 & 0.9184 \\
\hline Cch12 & 0.5397 & 0.0311 & 7.7969 \\
\hline Cch14 & 0.8818 & 0.0223 & 10.9394 \\
\hline CcC01471 & 0.3979 & 0.0528 & 4.4838 \\
\hline CcC02014 & 0.7835 & 0.0803 & 2.8635 \\
\hline CcC02069 & 0.4199 & 0.0698 & 3.3328 \\
\hline CC3754 & 0.6350 & 0.0368 & 6.5429 \\
\hline CC2448 & 0.2810 & 0.0920 & 2.4681 \\
\hline CC1944 & 0.8742 & 0.0466 & 5.1155 \\
\hline CC125 & 0.5600 & 0.0934 & 2.4253 \\
\hline Mean & 0.5836 & 0.0432 & 5.5323 \\
\hline
\end{tabular}

Table 5. Genetic variation within populations based on fourteen microsatellite loci.

\begin{tabular}{l|c|c|c|c|c}
\hline Population & $A$ & $A e$ & $H_{\mathrm{O}}$ & $H_{\mathrm{E}}$ & $P a$ \\
\hline SYG & 5.5714 & 3.4572 & 0.2566 & 0.6885 & 4 \\
\hline DAY & 6.0714 & 4.3748 & 0.2901 & 0.7674 & 23 \\
\hline WSK & 5.8571 & 3.8455 & 0.2792 & 0.7144 & 3 \\
\hline Across population & 5.8333 & 3.8925 & 0.2753 & 0.7234 & \\
\hline Species level & 6.6429 & 4.5939 & 0.2750 & 0.7636 & 30 \\
\hline
\end{tabular}

$A=$ Mean number of alleles; $A e=$ Mean effective number of alleles; $H_{\mathrm{O}}=$ observed heterozygosity; $H_{\mathrm{E}}=$ unbiased expected heterozygousity; $\mathrm{Pa}=$ number of samples with one or more private alleles.

Table 6. AMOVA analysis of genetic variances within and among populations.

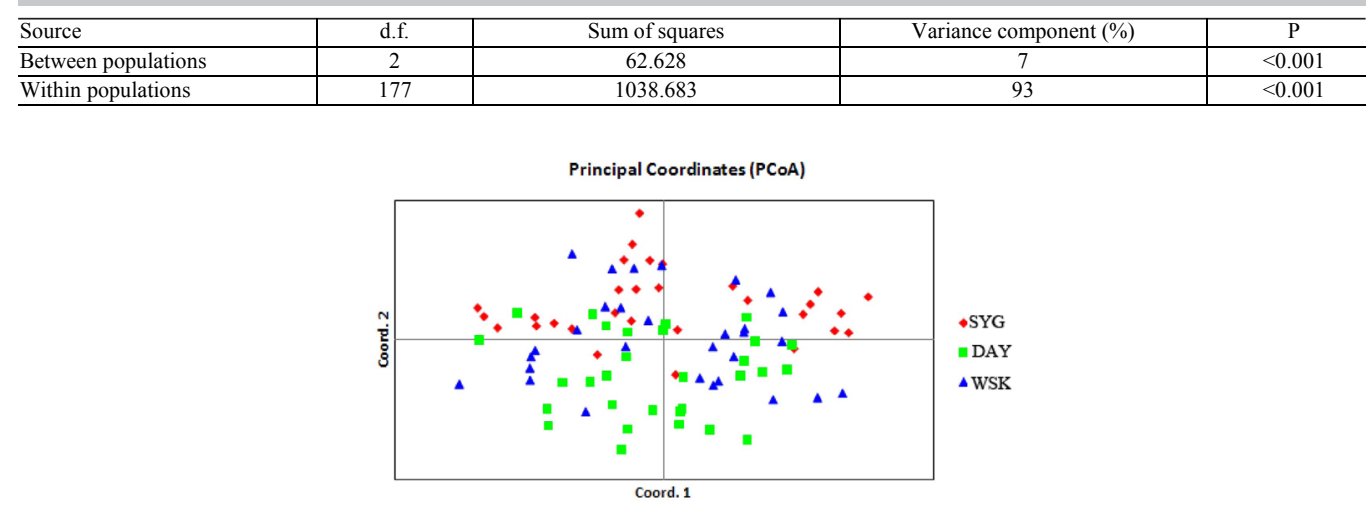

Figure 2. Principal coordinates analysis (PCoA) of all individuals. SYG, DAY and WSK stands for three populations. 
The observed number of alleles for one population varied from 5.5714 to 6.0714 , with an average of 5.8333, and the average effective number of alleles for one population varied from 3.4572 to 4.3748 , with a cross-population value of 3.8925 and a species-level value of 8. The observed and expected heterozygosities are presented in Table 5. The DAY population at medium altitude contained the highest genetic diversity, while the SYG population at low altitude had the lowest genetic diversity (Table 5). The number of samples with one or more private alleles in DAY was 23, which was much higher than in the other two populations (4 and 3). The high number of samples with private alleles in DAY was consistent with the high genetic diversity observed in this population.

\section{DISCUSSION}

Using 14 SSRs, 93 alleles were detected in 90 individuals from three populations of C. eyrei. The mean number of alleles per locus was 6.6 , and the ratio of polymorphic loci was $100 \%$. SSRs are used because of their codominant inheritance, multiallelic nature, abundance in the genome, and high reproducibility, but SSR marker development is time-consuming and costly. In this study, polymorphic SSRs were screened from the literature, indicating the transferability of SSRs from closely related species, which has also been found in other studies (Cui et al., 2008; Bhawna et al., 2015). Therefore, screening SSR markers from closely related species is a time- and money-saving method.

The polymorphism level of $C$. eyrei $\left(H_{\mathrm{E}}=0.7590\right)$ was similar to that of other tree species in the Castanopsis genus, such as $C$. acuminatissima (Blakesley et al., 2004) and $C$. fargesii (Xu et al., 2001). The average observed heterozygosity was lower than the average expected heterozygosity, which is consistent with results from other species in this genus (Vidhanaarachchi et al., 2005; Yamada et al., 2006). Our results suggest that genetic diversity in this species is relatively high $\left(H_{\mathrm{E}}=0.7590\right)$ compared to in other species. For example, the expected heterozygosity for Cyclobalanopsis myrsinaefolia is 0.553 (Liu et al., 2008), for Lithocarpus densiflorus it is 0.535 (Nettel et al., 2009), and for C. sclerophylla it is 0.568 (Wang et al., 2012). The high genetic diversity of $C$. eyrei is closely related to its biological characteristics. C. eyrei is a wind-pollinated species, with a long lifespan and wide geographical distribution, which have resulted in its high genetic diversity.

A large and significant deficit of heterozygosity was detected (0.612), which was consistent with the observed heterozygosity being lower than the expected heterozygosity. Positive $F_{i s}$ values have also been reported in several other species, such as Dactylis glomerata (Madesis et al., 2014) and Sesamum indicum (Wang et al., 2012). Significant deficits of heterozygosity may be indicative of inbreeding and/or the population substructure (Hartl and Clark, 1997).

The low mean $F_{s t}$ value $(0.0645)$ between the populations indicates that there is low genetic differentiation between them, and the AMOVA showed that $93 \%$ of the molecular variation was between all of the individuals while only $7 \%$ was attributable to variation between individuals from different locations.

We found that the medium-altitude population had the highest genetic diversity; a similar result was obtained for Quercus aquifolioides in Wolong Nature Reserve (Zhang, 2006). The high genetic diversity observed in the medium-altitude population may be attributable to the better habitat there. At medium altitude, there is less human disturbance than at low altitude, and the climate is not as harsh as at high altitude. In addition, population sizes at high and low altitudes are lower than at medium altitude, which would result in greater inbreeding; therefore, the medium-altitude populations of many species have the highest genetic diversity. 


\section{Conflicts of interest}

The authors declare no conflict of interest.

\section{ACKNOWLEDGMENTS}

Research supported by the Project Funded by the Priority Academic Program Development of Jiangsu Higher Education Institutions (PAPD) and the Science Foundation of the Chinese Academy of Science (\#30270110).

\section{REFERENCES}

Aradhya KM, Mueller-Dombois D and Ranker TA (1993). Genetic structure and differentiation in Metrosideros polymorpha (Myrtaceae) along altitudinal gradients in Maui, Hawaii. Genet. Res. 61: 159-159. http://dx.doi. org/10.1017/S0016672300031335

Bellusci F, Pellegrino G, Palermo AM, Gargano D, et al. (2005). Genetic differentiation of the endemic orophyte Campanula pollinensis along an altitudinal gradient. Plant Biosyst. 139: 349-356. http://dx.doi.org/10.1080/11263500500359409

Blakesley D, Pakkad G, James C, Torre F, et al. (2004). Genetic diversity of Castanopsis acuminatissima (Bl.) A. DC. in northern Thailand and the selection of seed trees for forest restoration. New For. 27: 89-100. http://dx.doi. org/10.1023/A:1025016331835

Bhawna, Abdin MZ, Arya L and Verma M (2015). Transferability of cucumber Microsatellite markers used for phylogenetics analysis and population structure study in bottle ground (Lagenaria siceraria (Mol.) Standl.). Appl. Biochem. Biotechnol. 175: 2206-2223.

Cao Q, Lu BR, Xia H, Rong J, et al. (2006). Genetic diversity and origin of weedy rice (Oryza sativa f. spontanea) populations found in North-eastern China revealed by simple sequence repeat (SSR) markers. Ann. Bot. 98: 12411252. http://dx.doi.org/10.1093/aob/mcl210

Cui XM, Dong YX, Hou XL, Cheng Y, et al. (2008). Development and characterization of microsatellite markers in Brassica rapa ssp. chinensis and transferability among related species. Agric. Sci. China 7: 19-31. http://dx.doi. org/10.1016/S1671-2927(08)60018-8

Doyle JJ and Doyle JL (1987). A rapid isolation procedure for small quantities of fresh leaf tissue. Phytochem. Bull. 19: 11-15.

Emanuelli F, Lorenzi S, Grzeskowiak L, Catalano V, et al. (2013). Genetic diversity and population structure assessed by SSR and SNP markers in a large germplasm collection of grape. BMC Plant Biol. 13: 39. http://dx.doi. org/10.1186/1471-2229-13-39

Fang YH (2005). Species composition and diversity of evergreen broad-leaved forest of Castanopsis carlesii and $C$. eyrei in Wuyishan National Nature Reserve, Fujian, China. Biodivers. Sci 13: 148-155. http://dx.doi.org/10.1360/ biodiv.040101

Gehring JL and Delph LF (1999). Fine-scale genetic structure and clinal variation in silene acaulis despite high gene flow. Heredity (Edinb) 82: 628-637.http://dx.doi.org/10.1046/j.1365-2540.1999.00524.x

Hartl DL and Clark AG (1997). Principles of population genetics, 3rd edition. Sinauer, Sunderland.

Hu ZH, Qian HY and Yu MJ (2009). The niche of dominant species populations in Castanopsis eyrei forest in Gutian Mountain National Nature Reserve. Acta Ecol. Sin. 29: 3670-3677.

Huang GM, Hong L, Ye WH, Shen H, et al. (2009). Isolation and characterization of polymorphic microsatellite loci in Castanopsis chinensis Hance (Fagaceae). Conserv. Genet., 10: 1069-1071.

Jin ZX (1998). Studies on Castanopsis eyrei community in the Tiantai Mountain of Zhejiang Province. J. Wuhan Bot. Res. 4: 317-324.

Jin ZX, Li JM and Pan GQ (2007). Primary study on genetic variation and genetic diversity among Castanopsis eyrei populations based on inter-simple sequence repeat (ISSR) markers. J. Zhejiang Univ. Sci. Ed. 34: 672-678.

Li C and Sun Y (2012). Transferability analysis of EST-SSR markers of Castanea mollissima to Castanopsis fargesii. Guihaia 32: 293-297.

Li JM and Jin ZX (2006). Genetic diversity of Castanopsis eyrei populations in three forest communities with different succession stage. J. Zhejiang Univ. 32: 232-236. 
Liu MH, Chen XY, Zhang X and Shen DW (2008). A population genetic evaluation of ecological restoration with the case study on Cyclobalanopsis myrsinaefolia (Fagaceae). Plant Ecol. 197: 31-41. http://dx.doi.org/10.1007/s11258007-9357-y

Madesis P, Abraham EM, Kalivas A, Ganopoulos I, et al. (2014). Genetic diversity and structure of natural Dactylis glomerata L. populations revealed by morphological and microsatellite-based (SSR/ISSR) markers. Genet. Mol. Res. 13: 4226-4240. http://dx.doi.org/10.4238/2014.June.9.8

Nei M (1987). Molecular Evolutionary Genetics. Columbia University Press, New York.

Nei M and Li WH (1979). Mathematical model for studying genetic variation in terms of restriction endonucleases. Proc. Natl. Acad. Sci. USA 76: 5269-5273. http://dx.doi.org/10.1073/pnas.76.10.5269

Nettel A, Dodd RS and Afzal-Rafii Z (2009). Genetic diversity, structure, and demographic change in tanoak, Lithocarpus densiflorus (Fagaceae), the most susceptible species to sudden oak death in California. Am. J. Bot. 96: 2224-2233. http://dx.doi.org/10.3732/ajb.0800339

Oyama K, Ito M, Yahara T and Ono M (1993). Low genetic differentiation among populations of Arabis serrata (Brassicaceae) along an altitudinal gradient. J. Plant Res. 106: 143-148. http://dx.doi.org/10.1007/BF02344418

Peakall R and Smouse PE (2012). GenAlEx 6.5: genetic analysis in Excel. Population genetic software for teaching and research--an update. Bioinformatics 28: 2537-2539. http://dx.doi.org/10.1093/bioinformatics/bts460

Qi-Lun Y, Ping F, Ke-Cheng K and Guang-Tang P (2008). Genetic diversity based on SSR markers in maize (Zea mays L.) landraces from Wuling mountain region in China. J. Genet. 87: 287-291. http://dx.doi.org/10.1007/s12041-008$\underline{0046-y}$

Ren Y and Xue JH (2008). The microclimatic characteristics of Castanopsis eyrei in a subtropical evergreen broad-leaved forest. J. Nanjing For. Univ. 32: 14-18.

Ren Y, Peng D, Pan JZ, Hong ZM, et al. (2010). Relationship between species biodiversity and biomass accumulation in a Castanopsis eyrei forest in Wuyishan Mountain under different temporal and spatial scales. Sci. Silvae Sinicae 46: 33-38.

Sáenz-Romero C and Tapia-Olivares BL (2003). Pinus oocarpa isoenzymatic variation along an altitude gradient in Michoacán, México. Silvae Genet. 56: 5-6.

Sáenz-Romero C, Guzmán-Reyna RR and Rehfeldt GE (2006). Altitudinal genetic variation among Pinus oocarpa populations in Michoacán, Mexico: implications for seed zoning, conservation, tree breeding and global warming. For. Ecol. Manage. 229: 340-350. http://dx.doi.org/10.1016/j.foreco.2006.04.014

Torres-Díaz C, Ruiz E, González F, Fuentes G, et al. (2007). Genetic diversity in Nothofagus alessandrii (Fagaceae), an endangered endemic tree species of the coastal maulino forest of Central Chile. Ann. Bot. (Lond.) 100: 75-82. http:// dx.doi.org/10.1093/aob/mcm073

Tóth G, Gáspári Z and Jurka J (2000). Microsatellites in different eukaryotic genomes: survey and analysis. Genome Res. 10: 967-981.http://dx.doi.org/10.1101/gr.10.7.967

Ueno S, Aoki K and Tsumura Y (2009). Generation of expressed sequence tags and development of microsatellite markers for Castanopsis sieboldii var. sieboldii (Fagaceae). Ann. Sci. 66: 509-530. http://dx.doi.org/10.1051/forest/2009037

Ueno S, Yoshimaru H, Kawahara T and Yamamoto S (2003). A further six microsatellite markers for Castanopsis cuspidata var. sieboldii Nakai. Conserv. Genet. 4: 813-815. http://dx.doi.org/10.1023/B:COGE.0000006120.99339.10

Vidhanaarachchi VRM, Baba S and Murayama S (2005). Genetic diversity of Castanopsis cuspidata (Thunb.) Schottky var. sieboldii (Makino) Nakai distributed in Ryukyu Islands, Japan. Jpn. J. Trop. Agr 49: 53-60.

Wang R, Compton SG, Shi YS and Chen XY (2012). Fragmentation reduces regional-scale spatial genetic structure in a wind-pollinated tree because genetic barriers are removed. Ecol. Evol. 2: 2250-2261. http://dx.doi.org/10.1002/ $\underline{\text { ece } 3.344}$

Wang XR and Szmidt AE (2001). Molecular markers in population genetics of forest trees. Scand. J. For. Res. 16: 199220. http://dx.doi.org/10.1080/02827580118146

Wright S (1965). The interpretation of population structure by F-statistics with special regard to systems of mating. Evolution 19: 395-420. http://dx.doi.org/10.2307/2406450

Xu LA, Li XJ, Pan HX, Zou HY, et al. (2001). Study on population genetic structure in Castanopsis fargesii with microsatellite markers. Acta Bot. Sin. 43: 409-412.

$\mathrm{Xu} \mathrm{XH,} \mathrm{Yu} \mathrm{MJ,} \mathrm{Hu} \mathrm{ZH,} \mathrm{Li} \mathrm{MH,} \mathrm{et} \mathrm{al.} \mathrm{(2005).} \mathrm{The} \mathrm{structure} \mathrm{and} \mathrm{dynamics} \mathrm{of} \mathrm{Castanopsis} \mathrm{eyrei} \mathrm{population} \mathrm{in} \mathrm{Gutian}$ mountain in natural reserve in Zhejiang, east China. Acta Ecol. Sin. 25: 645-653.

Yamada H, Ubukata M and Hashimoto R (2006). Microsatellite variation and differentiation among local populations of Castanopsis species in Japan. J. Plant Res. 119: 69-78. http://dx.doi.org/10.1007/s10265-005-0242-2

Yeh FC and Boyle TJB (1997). Population genetic analysis of codominant and dominant markers and quantitative traits. Belg. J. Bot. 29: 156-159.

Zhang XJ (2006). Genetic variation of Quercus aquifolioides populations at varying altitudes in the Wolong Nature Reserve of China. Graduate School of Chinese Academy of Sciences, Beijing.

Genetics and Molecular Research 15 (2): gmr.15028256 